\title{
Solidaridad y formas de construcción de poder en el dispositivo de la economía social y solidaria
}

Consideraciones en relación a un análisis de caso

Susana R. Presta

Doctora en Antropología (UBA)

IIGG-UBA/CONICET

E-mail: spresta@hotmail.com 
Resumen

En el marco de las sucesivas crisis y transformaciones en los procesos socioeconómicos, el desempleo y las distintas formas de precarización del trabajo han crecido en las últimas décadas. En especial, luego de la crisis del 2001 en Argentina, las iniciativas vinculadas a la llamada economía social y solidaria se han extendido como una forma "alternativa" a las consecuencias disgregadoras de la economía de mercado. Nuestras reflexiones parten del trabajo de campo realizado en una cadena de valor textil artesanal en la región del Valle de Punilla (Córdoba, Argentina). En el presente artículo, nos centraremos en el modo en que confluyen distintas racionalidades de gobierno y sus implicancias en las formas de construcción de subjetividades en la economía social y solidaria. Nuestra hipótesis plantea que las tensiones en relación al concepto de solidaridad, que surgen en las prácticas de los sujetos, se vinculan con la construcción de formas de poder "híbridas", sustentadas en la confluencia de distintas racionalidades de gobierno en el dispositivo estudiado.

\section{Palabras clave}

Economía social y solidaria

- Racionalidades de gobierno

- Relaciones de poder -

Ética de gobierno de sí
Abstract

In the framework of the successive crises and transformations in the socio-economic processes, unemployment and different forms of job insecurity have grown in recent decades. In particular, after the 2001 crisis in Argentina, the initiatives linked to the so-called social and solidary economy have spread as an "alternative" to the disruptive effects of market economy. Our considerations are based on our fieldwork in a traditional textile value chain in Punilla Valley region (Cordoba, Argentina). In this article, we will focus especially on the analysis of how different rationalities of government converge and its implications on the forms of construction of subjectivities in the social and solidary economy. Our hypothesis is that the tensions on the concept of solidarity arise in subjects' practices are linked to the construction of forms of power "hybrid", sustained by the confluence of different rationalities of government in the studied case.

Key words

Social and Solidary Economy Government Rationalities - Power Relations - Ethic of Self-government 


\section{Introducción}

La reestructuración neoliberal de la década de 1990 implicó una redefinición del papel del Estado en el desarrollo, la desregulación y el crecimiento de la competencia económica, la apertura comercial y la instauración de distintos acuerdos de integración regional. En este contexto de profunda crisis, surgen distintas formas de producción para la reproducción, ya sea con la expansión del mercado informal o bien con la creación de nuevas formas de cooperación que buscan reintegrar a los desempleados como productores/consumidores de bienes y servicios, a partir de soluciones sujetas a la satisfacción de necesidades y a la calidad de los vínculos socioculturales, que intentan apartarse de la lógica de la explotación del trabajo ajeno (Hintze, 2003).

El caso que analizamos en el presente artículo es una cadena de valor textil artesanal que se extiende a lo largo del Valle de Punilla (Córdoba, Argentina), articulada y consolidada a partir de la intervención del Instituto Nacional de Tecnología Industrial (INTI). Sus objetivos pueden resumirse con la siguiente cita: "La misión de Cadenas de Valor del INTI es la investigación, desarrollo, innovación y transferencia de metodologías y herramientas de extensión para la intervención en sistemas socio comunitarios de producción, con el propósito de favorecer y promover el autoabastecimiento de las comunidades y la recuperación como bien de cambio de los recursos locales transformados en productos, promoviendo la agregación in situ eficiente de valor y la distribución justa de la renta derivada" (Melaragno, 2011:92).

Las intervenciones de los agentes del INTI apuntan a formas precisas de control sobre las prácticas de los sujetos, justamente para aumentar la efectividad en función del logro de competitividad de los productos en los mercados formales (Melaragno, 2011:92), pero también implican la eficacia de una disciplina avocada a la construcción de este nuevo "trabajador emprendedor". Con énfasis en los procesos de aprendizaje y aspectos culturales de la población, la idea de “emprendedor" supone una ontologización de la iniciativa personal, 
pues los sujetos tienen en sus manos toda posibilidad de integración socioeconómica, aunque ésta se encuentre signada por la incertidumbre e implique la incorporación del trabajo humano en los procesos de valorización del capital ${ }^{1}$.

Si pensamos esto último en relación a la problemática que aquí trataremos, la forma de racionalidad ${ }^{2}$ orientada al modo específico en que se realizan la producción, distribución, intercambio y consumo, a partir de la organización socioeconómica que plantea la economía social y solidaria, coexiste en una relación de subordinación respecto de la racionalidad capitalista. Lo que se plantea es la existencia de una racionalidad empresarial y distintas racionalidades contrapuestas que se desarrollan dentro de los límites cambiantes que impone la lógica del mercado. Asimismo, esto conduce al intento de remediar la incertidumbre y el conflicto con un orden naturalizado de las cosas.

En virtud de esto último, analizaremos la "economía social y solidaria" en términos de dispositivo ${ }^{3}$, puesto que aúna y, también reconfigura, elementos de distintas racionalidades de gobierno. En este sentido, entendemos por "racionalidades de gobierno" aquellas estrategias de gobierno y construcción de las poblaciones según éstas se van delineando a partir de prácticas discursivas y extradiscursivas, que aunque sean pensadas conscientemente desde diversos dispositivos, se van configurando en un relleno estratégico que, en los hechos, va más allá de las decisiones conscientes de los individuos (Foucault, 2006 y 2007). Nos interesa, entonces, problematizar las contradicciones que resultan de dicha reconfiguración, para lo cual

1 Considérese la siguiente cita: “...el trabajo estable, heredero de la fase taylorista-fordista, está siendo sustituido por variados y diversificados modos de informalidad, de los que son ejemplo el trabajo atípico, los trabajos terciarizados, el 'cooperativismo', el 'emprendedurismo', el 'trabajo voluntario', etcétera. Esta nueva morfología del trabajo (...) ha ido ampliando el universo de trabajo invisibilizado, al tiempo que ha potenciado mecanismos generadores de valor (aunque bajo la apariencia del no-valor) haciendo uso de nuevos y viejos mecanismos de intensificación -cuando no de auto-explotación del trabajo" (Antunes, 2013:251).

2 Creemos importante considerar que el análisis de las racionalidades implica dar cuenta de cómo los sujetos concretos crean una realidad racional en el proceso histórico (Kosic, 1963).

3 Un dispositivo es un conjunto de elementos heterogéneos que comprenden discursos, instituciones, leyes, medidas administrativas, proposiciones filosóficas, morales, filantrópicas, entre otros. Los elementos del dispositivo pertenecen tanto a lo dicho como a lo no-dicho. Por consiguiente, el dispositivo es la red que puede establecerse entre estos elementos heterogéneos. Asimismo, puede permitir, justificar y ocultar una práctica o darle acceso a un campo nuevo de racionalidad (Foucault, 1984). 
hemos realizado nuestra investigación sobre un caso empírico, con el que podremos ahondar en la complejidad del tema abordado.

Desde el 2003, se encuentra en funcionamiento la Cadena de Valor Textil Artesanal, llevada a cabo en el Valle de Punilla, Córdoba, en el marco de la experiencia asociativa implementada por el trabajo conjunto entre Unidades de Extensión del Instituto Nacional de Tecnología Industrial (INTI) y del Instituto Nacional de Tecnología Agropecuaria (INTA) Cruz del Eje, Córdoba. El objetivo de la experiencia consiste en articular la producción ovina con el hilado de la lana y la confección de prendas tejidas. Esta experiencia forma parte de las actividades de extensión del INTI en economía social y tiene como propósito ofrecer una fuente de trabajo a partir de una tarea artesanal y un oficio ancestral que abarca a 120 trabajadores, a partir del desarrollo económico local.

Se utilizan protocolos de hilados diseñados por el INTI, la fijación del "precio justo" para cada tipo de hilado y el uso de un protocolo de gestión con el fin de permitir la participación y articulación de trabajadores alejados geográficamente, lo cual otorga un "sentido de pertenencia a la cadena".

Las producciones artesanales de las hilanderas, ya que el $90 \%$ son mujeres adultas, se comercializan en ferias, boutiques de la región y por internet. Según técnicos del INTI, el objetivo al principio fue facilitar la organización social de unidades productivas de subsistencia en una cadena de valor para producir textiles artesanales (fibras textiles, hilados y ropa), imitando la figura de fábrica a cielo abierto, que apela a recuperar conductas de organización basadas en la solidaridad y la ayuda mutua, sin perder de vista la eficiencia de los resultados económicos. Asimismo, informan que el proyecto se puso en práctica en una zona poco industrializada y con pocas oportunidades de empleo. Por tal razón, la prioridad es "aliviar la pobreza", reconstituyendo una actividad arraigada como la textil, con capacidad para que las mujeres complementen los ingresos de sus hogares.

Cada eslabón de la cadena se integra sobre corredores viales en una comarca de seis poblados vecinos con un sistema financiero propio basado en un "pacto social voluntario". De este modo, los par- 
ticipantes lograron incrementar la renta, mejorar la distribución y el precio de la lana local y el valor de la hora de trabajo. En este sentido, crearon un sistema de precios justos, idearon productos y mercados y una garantía solidaria en las transacciones, pactadas por medio de la palabra. La cadena incluye productores primarios, hilanderos, tejedores, comercializadores y técnicos que responden a un "nuevo patrón de comportamiento".

Las cadenas están organizadas en tres ejes denominados "bancos". En primer lugar, el Banco de Insumos Estratégicos se conformó a través de la Fundación "Saber Cómo" con un monto inicial de \$5.000 ayudando al establecimiento de un sistema financiero estructurado en bancos comunitarios de la lana articulados. Así, se logró organizar a productores ovinos para la mejora de la fibra de lana con la cual se abastecen los artesanos textiles. En segundo lugar, el Banco de Diseño y Asistencia Técnica a partir del cual se incorpora el uso de una rueca modificada por el INTI, que constituye una de las innovaciones tecnológicas de mayor impacto en la cadena. Dicha rueca modificada ha permitido aumentar la productividad del tiempo de hilatura y ha posibilitado la diversificación de tipologías de hilos a producir. Para la fabricación de la rueca, se capacitó y gestionó el armado de un taller de carpintería que genera trabajo para jóvenes judicializados del Hogar Taller "Sierra Dorada" (San Marcos Sierra). Tanto los ciclos de capacitación diseñados en relación con las necesidades de los distintos eslabones de la cadena, como la asistencia técnica continua, buscan la profesionalización de los distintos eslabones. Finalmente, el Banco del Agente Comercial se realizó con la profesionalización de un grupo de negocios promotores para la venta de los productos, mediante la introducción de tablas de costeo, organización de los productos en colecciones para la mejor tracción de ventas y el manejo de herramientas de marketing y administrativas.

Una vez consolidado el emprendimiento, el INTI se desvinculó y sólo mantiene una relación de consultoría con el mismo. En adelante, 
los integrantes de la cadena de valor textil adquieren financiamiento a través del Banco de la Buena Fe .

En el presente artículo, nos centraremos especialmente en el modo en que confluyen distintas racionalidades de gobierno y sus implicancias en las formas de construcción de subjetividades en relación a la economía social y solidaria. De este modo, nos interesa establecer las tensiones entre distintas racionalidades que atraviesan el emprendimiento estudiado en tanto consideramos que, a partir de las contradicciones que esto suscita, se consolidan estrategias de gobierno específicas, ancladas en la construcción de lo que denominamos una "ética de gobierno de sí". Asimismo, en relación a esto último, problematizaremos en torno a la noción de "solidaridad" en la economía social y solidaria y las paradojas que alberga en las prácticas y discursos de los sujetos.

\section{Paradojas de la solidaridad y formas de construcción de poder}

La economía de Capilla del Monte está ligada en un alto porcentaje a la actividad turística de carácter estacional, modalidad que ha sufrido altibajos en los últimos años. El circuito económico asociado al mismo está compuesto, principalmente, por actividades comerciales y de servicios, las cuales también presentan una importante disminución. De modo que la población no cuenta con ingresos significativos que posibiliten mantener una economía estable durante el resto de la temporada baja. Por dicha razón, las integrantes de las unidades domésticas analizadas han optado por incorporarse a la cadena de valor textil como un modo de complementar sus ingresos. Sumado a esto, actualmente, no existe en la localidad un sector industrial.

4 Los Bancos de la Buena Fe forman parte de una iniciativa del Ministerio de Desarrollo de la Nación. Para obtener un préstamo inicial de alrededor de $\$ 750$ (que puede incrementarse en función de la buena conducta de pago del grupo), los emprendedores deben presentan un proyecto que detalle el tipo de producción a realizar, perspectivas de inserción en el mercado y sustentabilidad del mismo. Los montos no están sujetos a intereses y se otorgan a grupos de cuatro o cinco integrantes. La garantía de pago es, precisamente, el grupo mismo, puesto que la deuda se asume colectivamente y, si un integrante no puede cubrir su cuota, el resto del grupo asume su deuda. 
Históricamente, en los años 50 y 60, Capilla del Monte era una de las atracciones turísticas más importantes de los sierras de Córdoba. La temporada comenzaba a fines del mes de Noviembre y culminaba a mediados del mes de Abril del año siguiente. Durante esta época de esplendor, los propietarios ampliaron sus viviendas y crearon pensiones y hosterías. En la década del 70, proliferaron las industrias familiares de artículos regionales, tejidos y de alimentos, e industrias medianas como Alfajores El Zapato, Industria Bal-Ros, Agua San Salvador, Metalúrgica Power y "El Frigorífico", las cuales no sólo generaron una fuente de empleo sino que también posibilitaron la trascendencia de la localidad a través de los productos elaborados. También se incrementó el personal en empresas estatales como E.N.Tel, E.N.Co.Tel., Ferrocarriles, entre otras. A su vez, aparecen las colonias de los distintos sindicatos. Sin embargo, en la década del 90, a partir del avance de las políticas neoliberales, la mayoría de las pequeñas y medianas industrias cierran sus puertas, como así también, las empresas estatales pasan a manos de capitales privados generando una fuerte expulsión de fuerza de trabajo. En consecuencia, desde entonces, prevalece el subempleo. Actualmente, la Municipalidad es la entidad que absorbe la mayor cantidad de fuerza de trabajo, junto con escuelas públicas y privadas. Asimismo, en los últimos tres años, se ha producido una notable inmigración de familias provenientes de las grandes ciudades, lo cual ha incentivado el sector de la construcción y el mantenimiento de viviendas familiares.

En este contexto, las tejedoras e hilanderas entrevistadas cuentan, en la mayoría de los casos, con otro empleo (maestras en escuelas públicas o privadas, empleadas de comercio), o bien son jubiladas, feriantes en temporada de turismo, amas de casa o realizan lo que llaman "changas".

A partir de nuestro trabajo de campo, hemos podido observar que los integrantes de la cadena de valor textil conservan la propiedad de sus medios de producción que son adquiridos, en un primer momento, mediante inversiones propias. Al insertar la producción en el mercado, el ciclo de inversiones se renueva con la compra de materias primas para reiniciar los procesos de trabajo en función de una 
maximización de los beneficios, a la vez que sostiene los vínculos socio-afectivos del grupo. Un porcentaje del dinero requerido para tal inversión, como también para el pago de alquiler y gastos impositivos de los locales-boutiques donde se comercializan parte de las prendas e hilados, se obtiene a partir de préstamos otorgados por el Banco de la Buena Fe, lo cual genera una espiral de constante endeudamiento. En este proceso, los integrantes asumen por completo los riesgos de producción. La relación, antes descripta, entre los procesos de trabajo y el mercado, posibilitan formas de reproducción de la fuerza de trabajo que, al prescindir de una relación salarial, transfieren los costos tanto de la producción como de la reproducción social hacia los propios productores.

En el trabajo de campo realizado en los años 2013 y 2014, las entrevistadas expresaron que el local-boutique representó serios problemas a la hora de afrontar los gastos (monotributo, impuestos, alquiler). De las seis personas que participaban en la boutique, sólo quedaron dos debido a la imposibilidad de sostener el local económicamente. Las deudas contraídas impidieron que pudiesen retirar las prendas e hilados del local y las dos personas que permanecieron a cargo del mismo, vendieron los productos sin compartir las ganancias con sus compañeras menos afortunadas. Con el fin de solventar los riesgos del negocio, se incorporaron hilados y tejidos industriales de procedencia china y boliviana, sahumerios, accesorios como collares y aros que, según las trabajadoras del emprendimiento, tergiversaron el sentido del mismo.

Este hecho generó un fuerte conflicto definido por las entrevistadas en términos de "egoísmo y competencia". Prevén una sanción (suspensión) de las dos integrantes que llevaron a cabo la mencionada "estrategia de negocio" y que atenta contra los "principios solidarios" del emprendimiento.

Con la aprobación de la marca colectiva, pueden participar en eventos que organiza el Ministerio de Desarrollo Social de la Nación,

5 Los testimonios, frases y palabras encomillados comillas refieren a relatos y expresiones de las tejedoras e hilanderas entrevistadas. 
lo cual le "otorga más formalidad al emprendimiento". Las boutiques fueron cerrando poco a poco debido a la imposibilidad de asumir los riesgos económicos y retornaron a la vieja práctica de vender en sus propios hogares, a la vez, que realizan exportaciones de pequeñas cantidades de hilado (de 10 a 12 kilos de lana) a España y Francia. A pesar de que la situación actual del emprendimiento resulta conflictiva y las ventas en general han disminuido, la identificación con el INTI en términos de "una familia" no se ha visto afectada e incluso consideran que han "faltado" al sistema ético, basado en el amor, la responsabilidad, la tolerancia, el compromiso, la solidaridad, que "les han enseñado"; situación que ha generado en las entrevistadas una sensación de malestar emocional. Si bien, el sistema ético, resulta en un parámetro que mide lo "correcto" de lo "incorrecto", los intersticios del poder abren paso a profundas paradojas. Durante las entrevistas afirmaron "es más fácil estar en relación de dependencia". Consideremos el siguiente testimonio:

A mí me encanta. Ya pasa de ser un trabajo, para mí es parte de mi vida, de mis sueños, mis pensamientos. Yo por razones personales, estoy un poquito decaída. Después de diez años casi que estamos con el proyecto, estoy en un momento de baja. Pero con grandes planes, por ejemplo, estoy estudiando computación para hacer todas las planillas (...) Entonces yo ya estoy pensando en una nueva etapa. Hacerlo más organizado, más rápido, más... Para mí, es como parte de mi vida. Si me vienen bien las ventas que hago, no te voy a decir "Ah, no me importa el dinero". (Testimonio hilandera/tejedora y referente, año 2013)

En nuestro caso, la racionalidad capitalista confluye en la idea de que cada trabajador pueda ser, al mismo tiempo, un empresario, paradójicamente, manteniendo elementos propios de una economía del don a través de la entrega de tiempo de trabajo, el don de sí y la relación constante de deuda. El don de sí implica la entrega de sí mismo, es decir, sus afectos y sus pasiones puestos en manos de un fin y una tarea que los trasciende: la construcción de una "Otra Economía" 
como un horizonte ideal en términos de la coexistencia contradictoria de los imperativos de desenvolver la individualidad y ser-solidario.

Según Godelier (1996), el don aproxima a los protagonistas porque se constituye en reparto y los aleja socialmente porque hace de uno el deudor del otro. El don es, en este sentido, una práctica ambivalente pues puede unir pasiones y fuerzas contradictorias o contrarias. Puede ser, al mismo tiempo, un acto de generosidad y de una violencia disfrazada de gesto desinteresado, ya que se ejerce por medio y bajo la forma de reparto. Si bien el don puede oponerse a la violencia directa, a la subordinación física, material y social, también puede transformarse en su sustituto. Si tenemos en cuenta con Godelier (1996), el don en tanto utopía, como último refugio de la solidaridad, podemos, en nuestro caso, notar su instrumentalización en el dispositivo de la economía social, si la consideramos en términos de una estrategia de gobierno. El don se convierte en una condición socialmente necesaria frente al sentimiento de desamparo en contextos de crisis, al tiempo que, paradójicamente, es recreado como un medio para la inserción en el mercado.

Cabe señalar que Elizalde Hevia (2011) sostiene que la solidaridad está anclada en nuestra propia naturaleza que se hace presente ante nuestra conciencia en la forma de emociones, ideas, sentimientos que se expresan en conductas y conforman una realidad antropológica y ética. Por tanto, en el contexto de globalización y exclusión hay una "mayor demanda de solidaridad" (Elizalde Hevia, 2011:34).

Respecto de la economía solidaria, Razeto Migliaro (2013) plantea que las actitudes que adoptamos cuando pensamos, sentimos, aprendemos, proyectamos, amamos, actuamos, conocemos y nos relacionamos, determinan nuestros éxitos y nuestros fracasos. En este sentido, propone el deber de "trabajar sobre sí mismo" para distinguir a las personas que son y quieren ser constructores de una nueva civilización. En concordancia con esto, será necesario "un proceso de purificación de la conciencia, de desarrollo espiritual, que implica la mitigación de los intereses individuales y la superación del egoísmo y la mezquindad” (Razeto Migliaro, 2013:52). 
En el dispositivo de la economía social y solidaria, la colonización de los afectos en función del rendimiento económico, la productividad y la eficiencia, se conjuga con la construcción de una ética de gobierno de sí, la cual tiende al aumento de las formas de autoexplotación para garantizar la permanencia de los sujetos en términos de consumidores y productores en el mercado. Podemos pensar que el desempleo y la incertidumbre ${ }^{6}$ devienen mecanismos de regulación y autorregulación naturalizados en términos de libertad y autonomía.

La centralidad del sentimiento de solidaridad en la economía social y solidaria, ha sido tratada en numerosos estudios (Razeto, 1997; Gaiger, 1999; De Melo Lisboa, 2004, entre otros). Dado que el factor escaso es el cariño y la atención humana, es decisiva la "ingeniería del vínculo social” (De Melo Lisboa, 2004:392). El individualismo exacerbado como antesala de profundas crisis en términos sociales, conduce a plantear la relación entre autonomía y solidaridad. En el contexto actual de crisis, De Melo Lisboa (2004) sostiene que la solidaridad es un objetivo civilizatorio. La ética de la solidaridad es la ética del amor, incluyendo en un extremo al difícil amor hacia los enemigos. Y agrega, además, que ésta es la ética que necesitamos desarrollar si queremos sobrevivir. Retoma la idea "simpatía" de Adam Smith para concluir que al incrementar nuestra sensibilidad progresamos moralmente.

Para De Melo Lisboa (2004), la solidaridad como valor universal y la conveniencia social y económica de que los principios de competencia y cooperación (o solidaridad) coexisten. Se construyen, así, relaciones de subordinación basadas en relaciones paradojales que derivan en la preeminencia de mecanismos de regulación del mercado, tal como la competencia, apelando, al mismo tiempo, a la universalidad de la solidaridad.

En el marco de las prácticas cotidianas de los sujetos que participan en el emprendimiento analizado, dicha coexistencia provoca

\footnotetext{
6 El factor incertidumbre posee una notable importancia en el neoliberalismo, que nos permite relacionarlo con la teoría subjetiva del valor. En esta última, la producción ya no es fruto del trabajo; ahora la producción o su crecimiento monumental es consecuencia del uso del capital, del tiempo de espera del capitalista, del riesgo que corre el capitalista, de la incertidumbre en la calidad y cantidad de la producción que éste genera (De Büren, 2011).
} 
indefectiblemente conflictos. El emprendimiento del Valle de Punilla fue "pionero" en revitalizar la actividad textil en la zona. Sin embargo, en los últimos años, surgieron "réplicas" del emprendimiento en distintos puntos del Valle de Punilla e, incluso, en otras provincias. Estos nuevos emprendimientos, comercializan los hilados y prendas a precios menores. La disputa por ganar terreno en el mercado, produjo divisiones en el grupo analizado. Una parte del grupo -por cuestiones "éticas”, según afirman en las entrevistas- continuó comprando la materia prima ( $\$ 55 \mathrm{~kg} / \mathrm{lana})$ al proveedor inicial, con el cual tenían un acuerdo a través del INTI. Sin embargo, otra parte eligió cambiar de proveedor ( $\$ 35 \mathrm{~kg} / \mathrm{lana}$ ). Razón por la cual, en un mismo emprendimiento, unos obtienen más ganancias que otros. Asimismo, en las entrevistas, expresaron que hubo la intención de reunirse y negociar el precio de la materia prima, sino que cada uno decidió lo que convenía a sus intereses. Una de las entrevistadas nos decía: "la cuestión era no esclavizarnos a nosotras mismas. Si no aumentamos los precios, estaríamos siendo iguales a lo que estamos en contra...que no haya esa esclavitud". La creciente competencia las obliga no sólo a incrementar los precios, sino a aumentar el tiempo de trabajo para producción de hilados y prendas. Frente a esta situación, los técnicos del INTI recomendaron que revean sus actividades en función de la demanda del mercado. Algunas de ellas empezaron a confeccionar prendas con tela y tejidos más finos, que implica usar lanas industriales o semi-industriales. Dado que la actividad fundamental del emprendimiento es el hilado, esto provocaría que muchas hilanderas tengan que transformarse en tejedoras. En el marco de este contexto, una entrevistada declaró: "el sentido cooperativo se ha desgastado". Y agregó: "cada cual piensa en lo de uno. Hay que ser individuales pero, a la vez, conectarse con los demás. Hay muy buenos sentimientos en determinadas personas. Pero llegado el momento, cada uno arregla para lo suyo". Se atribuye esta coexistencia de la solidaridad/ competencia a la actual crisis y la endeble situación económica de los integrantes del emprendimiento. Razón por la cual, una cantidad considerable de ellos tuvieron que buscar empleo en el sector público o comercial. Resulta interesante notar que la conclusión radica en 
"ser flexible y cambiar". Sin embargo, los comentarios respecto de la economía social y solidaria, se asientan sobre una crítica: "yo creo que se aprovechó o se usó que fue muy buena la idea de hacer estos emprendimientos. Pero, después, es como que plantaste la semilla, tienes la plantita pero no la riegas más, la dejas, a ver si se riega sola” (Testimonio, hilandera, 2014).

Podríamos pensar que se construye el ejercicio de un tipo de coacción sobre el "sentido moral" que configura las formas de gobierno de sí mismo. Se trata de condicionar el modo en que se percibe una acción o sentimiento, propio o ajeno, a partir del establecimiento de la "creencia" de que determinados sentimientos morales son, de hecho, universales. Se desestima la constitución histórica de los sujetos y los condicionantes estructurales que atraviesan sus prácticas, al tiempo que se sostiene un objetivo civilizatorio que implica un deber-ser ideal. Esta coacción trata de moldear el carácter conflictivo e incalculable de las pasiones humanas, al investir de universalidad a determinados sentimientos. De manera que los procesos de constitución histórico-social de los sujetos que solapado bajo formas de naturalización de determinados modos de ser y hacer. Esto, a su vez, se complementa con la construcción de un modo de sujeción basado en la regulación y autorregulación de la esperanza, de la creencia en la posibilidad de "otra economía". Esperanza que dirige los modos de percibir y significar la relación de los sujetos consigo mismos y con los demás.

Los discursos que promulgan la esperanza de la consolidación de “otra economía”, capaz de superar el carácter disgregador de la lógica del mercado y las prácticas asociadas al afán de lucro y consecución del interés privado, paradójicamente, no cuestionan el hecho de que las organizaciones de la economía social y solidaria compiten por insertar sus producciones en el mercado, pues no se limitan al autosubsistencia7. El poder de gobierno de sí anclado en esta creencia -que termina por convertirse en una verdad práctica- conlleva,

7 Nos referimos al hecho de que la producción no está destinada al uso o consumo personal, sino que se ajusta a requerimientos de la demanda en el mercado. 
asimismo, un control sobre los otros, a partir de la aprobación o desaprobación de sus prácticas en función de las percepciones en torno a los sentimientos morales que las guían. Las formas de interpelación ética se basan en la capacidad de cambiar las formas de percepción del mundo objetivo, es decir, en el gobierno del poder-ser.

Precisamente, Zižek (2008) sostiene que "la lucha por la hegemonía ideológico-política es siempre una lucha por la apropiación de aquellos conceptos que son vividos 'espontáneamente' como 'apolíticos', porque trascienden los confines de la política” (Zižek, 2008:15). Consideramos, entonces, que la noción de solidaridad se ha transformado, en la racionalidad de gobierno neoliberal, en una noción cuya eficacia simbólica radica en la ficticia igualación de los intereses de la clase trabajadora con los intereses de los sectores hegemónicos.

En este sentido, "cualquier universalidad que pretenda ser hegemónica debe incorporar al menos dos componentes específicos: el contenido popular 'auténtico' y la 'deformación' que del mismo producen las relaciones de dominación y explotación” (Zižek, 2008:19). El gobierno de lo posible, del poder-ser a partir de la mencionada coacción del sentido moral, trastoca la contradicción en complementariedad como forma de gestionar el conflicto social a partir de la reapropiación de los sentidos y reivindicaciones de la clase trabajadora.

Actualmente, podríamos decir que, en el caso de la economía social y solidaria, la búsqueda de una plenitud de sentido se centra en la necesidad de vincularse con el mercado, ya no como trabajadores asalariados sino como "emprendedores", en tanto promesa de un trabajo emancipado de las cadenas del trabajo asalariado (futuro en construcción). Promesa anclada en una contradicción que la economía social y solidaria, por el momento, no logra sortear.

Si nos remontamos a los antecedentes de la economía social en el siglo XIX, encontramos que tanto Fourier como Owen, coinciden en la idea de "felicidad" puesto que, de otro modo, los pobres -la clase trabajadora- se avocarían al robo, al odio y la rebelión (Fourier, 1989). Según el autor, el objetivo de todo orden social es conciliar lo pasional y lo material, vale decir, aunar las pasiones, gustos, instintos, caracteres y la diversidad. Por lo tanto, al igual que Owen, 
habría un interés especial por la regulación de las pasiones humanas que, en el caso de Fourier, apunta a transformar el trabajo en placer ${ }^{8}$. En este sentido, para Fourier (1989) el Estado societario que plantea no admite, por entero, la igualdad. La desigualdad de condiciones y disparidad de caracteres es un medio esencial, por lo cual resulta necesario incentivar la desigualdad. En este marco, la asociación sustituye la competencia individual, insolidaria, falaz y arbitraria por una competencia corporativa, solidaria, verídica y garantizada. La desigualdad y la competencia no desaparecen, sólo son resignificadas bajo los imperativos de la asociación, la regulación de las pasiones y la armonía social'.

Justamente, según Fourier (1975) la armonía necesita amor, que es identificado como una pasión divina. Se trata de la pasión que mejor nos identifica con Dios, que nos hace participar de su esencia. De modo que, el egoísmo denota la ausencia de Dios y, en este sentido, podemos pensar cierta relación con Feuerbach.

Si Dios es la esencia objetivada del hombre, entonces, el hombre para el hombre, es Dios. Para Feuerbach (2006) en su libro La esencia del cristianismo [1841], la esencia del hombre ${ }^{10}$ de la cual él es consciente, consiste en la razón, la voluntad y el amor. Razón, voluntad y amor son la esencia absoluta del hombre como hombre y el fin de su existencia (Feuerbach, 2006:15). En este sentido, sólo en la conciencia se manifiesta el valor del ser, el valor de la naturaleza. Por tanto, el amor, para Feuerbach (2006), será el vínculo entre lo general y lo individual, puesto que el otro hombre es el vínculo entre yo y el mundo. De modo que "el hombre es a la vez para sí mismo el yo y

8 Resulta interesante notar que para el caso estudiado se plantea que uno de los rasgos interesantes radica en "la experimentación de sensaciones de placer y satisfacción personal asociados a la evidencia de una optimización de las técnicas, la organización del trabajo y la consolidación de rutinas" (Melaragno, 2011:98)

9 Nótese que tanto para von Hayek como para von Mises, si bien bajo formas diferentes, la desigualdad y la competencia son constitutivas del orden del mercado. Por supuesto, von Mises (1986) criticará a Fourier puesto que no tiene en cuenta el criterio de escasez, que le conduce a sostener que la falta de abundancia se debe a imperfecciones del sistema capitalista de producción. Pero más allá de las diferencias, los une el anhelo de una sociedad sin conflictos, armónica.

10 Según Marx, "Feuerbach diluye la esencia religiosa en la esencia humana. Pero la esencia humana no es algo abstracto inherente a cada individuo. Es, en su realidad, el conjunto de las relaciones sociales" (Marx, 1980:56). 
el tú; él puede colocarse en el lugar del otro, precisamente porque no solamente su individualidad, sino también su género y su esencia, son los objetos de su reflexión ${ }^{11}$ " (Feuerbach, 2006:14). En este sentido, podríamos trazar una relación entre Feuerbach y la importancia del "amor" en los socialistas como Fourier. Según Feuerbach, “yo existo y me siento dependiente del mundo porque primero me siento dependiente de otros hombres (...) Me reconcilio con el mundo mediante el otro hombre (...) Sólo en el otro, el hombre es consciente de sí mismo; pero sólo cuando sea consciente de mí mismo, soy consciente del mundo" (Feuerbach, 2006:100).

En la precedente cita, el autor refiere a que el primer objeto del hombre es el hombre -donde podemos notar una influencia kantiana: el hombre como fin, no como medio-, por esto, la ley suprema del hombre, es el amor del hombre al hombre. Lo que se mira, se aprecia; contemplar es reconocer (Feuerbach, 2006:135). De lo contrario, el mundo sería un absurdo. Por consiguiente, el egoísmo es una fuerza destructora que consagra a la muerte lo que la teoría amorosa devuelve a la vida. El amor es sólo idéntico con la razón, ambos son libres y universales. Razón y amor, dos conceptos que también adquieren un carácter universal en los llamados "socialistas utópicos"12.

11 Resulta interesante notar que este "ponerse en el lugar del otro" podría relacionarse, en cierto sentido, con la idea de simpatía desarrollada por Adam Smith (2009), la cual se diferencia de la idea de benevolencia (Hume, 1984). La simpatía implica ponerse en el lugar del otro y asumir su situación. Hume (1984) sostenía que las dos pasiones humanas más fuertes son el egoísmo (deseo de ganancia) y la benevolencia (asociada a la filantropía) y, justamente, lo importante remitía a la coincidencia de ambas pasiones ya que de ello dependía la seguridad de la propiedad privada. Hume, teniendo en mente al individuo libre del pacto social, plantea que la benevolencia sirve para refrenar el egoísmo, así permite que se establezca una convención compartida y establecida por la razón en base al sentimiento de benevolencia. En cambio, el concepto de simpatía en Smith sólo cabe abordarlo subjetivamente, es decir, asumiendo los sentimientos y circunstancias del otro. La simpatía no es perfecta, no podemos con exactitud saber cómo se sienten otras personas, pero la clave es ponerse en el lugar del otro y asumir su situación. El amor propio es compatible con la simpatía, es decir, la preocupación por uno mismo es compatible con la preocupación por los demás. Hume habla específicamente de la idea de simpatía en términos de un principio vivificante de todas las pasiones humanas. Sostiene que ninguna pasión tendría fuerza alguna si hiciéramos entera abstracción de los pensamientos y sentimientos de otras personas (Hume, 1984:553).

12 Marx y Engels (1959) realizan una crítica al "verdadero socialismo" (1844) alemán (con fuerte influencia de Feuerbach). Los "verdaderos socialistas", retoman algunos aspectos de Saint-Simon, Fourier y Owen, es especial, las ideas de armonía y cohesión. En La ideología alemana, Marx y Engels (1959), plantean que la proclamada "cohesión natural” y "unidad humana natural”, paradójicamente, descansan sobre la servidumbre feudal, la esclavitud y toda clase de desigualdades sociales de todas las épocas. De modo que las relaciones comunes a los hombres aparecen, pues, como productos de la "esencia del hombre", de la naturaleza, cuando en realidad son, lo mismo que lo es la conciencia de la igualdad, productos históricos. El "verdadero socialismo" postula la emancipación del proletariado 
Ahora bien, respecto del carácter universal de determinados sentimientos, resulta importante considerar lo que señala Zižek: "La vocación específicamente humana no radica en el desarrollo de las potencialidades inherentes al hombre (no radica en el despertar de las fuerzas espirituales dormidas $o$ de cierta programación genética); se dispara por un encuentro traumático externo, por el encuentro con el deseo del Otro en su impenetrabilidad (...) en la ideología del sujeto como el individuo psicológico trufado de destrezas y tendencias naturales, entonces, interpreto, cuasi automáticamente, todos estos cambios como resultados de mi personalidad, no como resultado de que las fuerzas del mercado me estén arrojando de acá para allá” (2004:59-137).

Según el autor, el liberalismo -y, cabe pensar, el neoliberalismointerpela al sujeto en nombre de su propio bien. Se aferra a la ficción de la inmediata autopercepción del sujeto como libre, que acepta lo que se les ha impuesto como algo que tiene su origen en su propia "naturaleza" (Zižek, 2004). Esto último, no sólo podría vincularse con el análisis que Marx (2001) realiza en relación a los procesos de subsunción del trabajo al capital, a partir de los cuales las fuerzas productivas del trabajo aparecen como fuerzas productivas del capital sino que, desde nuestra perspectiva, también se vincula con la construcción de un ontopoder ${ }^{13}$. Así, egoísmo/generosidad, solidaridad/competencia, ambición/austeridad, no sólo coexisten de modo contradictorio, sino que también, son investidos de un carácter universal, transhistórico, es decir, se considera que los sujetos naturalmente poseen dichos sentimientos o valores.

Dicho ontopoder forma parte de lo que denominamos como un entramado complejo de "poderes híbridos", a saber, la confluencia de heterogéneas racionalidades de gobierno que sintetizan su coexis-

mediante la transformación económica de la producción por la liberación de la humanidad por medio del “amor" (Engels, 1980). Según Engels, para Feuerbach, la religión es la relación sentimental que, hasta ahora, buscaba su verdad en un reflejo fantástico de la realidad (en la mediación de uno o muchos dioses), y que termina por encontrar directamente en el amor entre el yo y el tú (Engels, 1980:27). Engels (1980) acusa a Feuerbach de divinizar los sentimientos, de transformar toda unión entre hombres en una religión, dado que ansía la reconciliación universal en un mundo dividido en clases e intereses antagónicos, con el poder único del arma del "amor".

13 Para un análisis más detallado véase Presta (2013). 
tencia contradictoria constituyéndose en formas de poder que, por su constitución a partir de elementos contradictorios, son desapercibidos y, cuya ausencia es en sí misma, su presencia velada. Las formas de poder híbrido se "escurren" en las prácticas y en los discursos. Son percibidos allí donde dichas prácticas y discursos entran en crisis. Dicha presencia en ausencia, se constituye como un modo de naturalizar su ejercicio y poner, de ese modo, el gobierno de sí en un primer plano puesto que se establecen, de manera implícita o explícita, determinadas responsabilidades u obligaciones ("gestión de las propias necesidades") que los sujetos podrán cumplir al apropiarse de las mismas bajo la forma de un ejercicio de autocontrol sobre los propios afectos, valores e intereses.

Podemos pensar que la racionalidad de gobierno neoliberal cultiva un arte de construir conceptos contradictorios que unen y afirman ideas contrarias, por ende, este arte requiere instaurar la creencia de que dichos conceptos son verdaderos. Dichas formas de poder híbrido se ejercen en y por la contradicción. Nos referimos, precisamente, a que las relaciones de poder se construyen en la coexistencia contradictoria de sentimientos (solidaridad/competencia) y prácticas (producción para el autoconsumo, al tiempo que se otorga prioridad de la producción orientada a una economía de mercado) que suscita la economía social y solidaria. Cuando decimos por la contradicción queremos plantear que, gracias a la instauración de dichas contradicciones (coexistencia de ideas contrarias que no se resuelven de manera sintetizadora), las relaciones de poder resultan difícilmente distinguibles y se construyen sobre la base de la existencia de dichas contradicciones que, cada vez, se afianzan más en la praxis social y son, al mismo tiempo, incentivadas desde el "saber experto" de técnicos y funcionarios de organismos nacionales e internacionales. Nuestro planteo radica en que las contradicciones que se generan en las prácticas concretas, los sentidos que se construyen, las relaciones con los otros y con sí mismos, son parte constitutiva de las actuales formas de gobierno de la fuerza de trabajo. El predominio de la dimensión ética y moral -que al nutrirse de elementos heterogéneos (liberales, del socialismo cooperativo, cristianos, neoliberales) produce 
tensiones y contradicciones en los procesos de subjetivación- resulta en una ontologización de determinados afectos o sentimientos, a la vez que, naturaliza el orden del mercado, paradójicamente, oponiéndose al mismo.

\section{A modo de cierre}

No existen prácticas que sean independientes del conjunto de relaciones históricas en las cuales funcionan. Por eso, aunque las prácticas son singulares y múltiples, es necesario estudiarlas como formando parte de un ensamblaje, de un dispositivo que las articula. Es por ello que hemos analizado la "economía social y solidaria" en términos de dispositivo, puesto que aúna, y también reconfigura, elementos de distintas racionalidades de gobierno.

El proceso de articulación de las unidades domésticas (en nuestro caso a partir de procesos de trabajo vinculados a la producción textil) en los flujos del mercado, a través del dispositivo de la economía social y solidaria, incide en la construcción de distintas formas de subjetividad ancladas en la idea de "emprendedor". Dichas formas de construcción de subjetividad se encuentran atravesadas por una interpelación afectiva de los sujetos involucrados en el emprendimiento sobre el imperativo de lo que Razeto Migliano (2013) denomina el "trabajo sobre sí mismo". Este "deber" centrado en el sentimiento de solidaridad en tanto mecanismo de selección para distinguir aquellos que quieren construir una "nueva civilización" y aquellos que no lo quieren así, apela a la construcción armónica de las relaciones sociales, paradójicamente, constituyéndose sobre las contradicciones propias de la economía de mercado. Esto último, implica un proceso de construcción subjetiva diverso, el cual se sostiene sobre la transformación del sentido del concepto de "trabajo" y la colonización del sentimiento y discursos en torno a la "esperanza" (por agentes públicos e, indirectamente, por agentes privados), como así también, postula reconfiguraciones en la construcción de relaciones de poder a partir de una "ética de gobierno de sí mismo". 
Anteriormente, mencionamos el siguiente testimonio de una tejedora: "cada cual piensa en lo de uno. Hay que ser individuales pero, a la vez, conectarse con los demás. Hay muy buenos sentimientos en determinadas personas. Pero llegado el momento, cada uno arregla para lo suyo". A partir de esto último, podemos sintetizar el modo en que actúa el ejercicio de los poderes híbridos, conformados por la confluencia, incluso contradictoria, de elementos distintas racionalidades de gobierno. Así, el postulado liberal que sostiene que al perseguir su propio interés, los individuos promueven el interés de la sociedad de una manera más efectiva que si esto entrara en sus designios (Smith, 1958), o dicho con otras palabras, el hecho de que al buscar el propio beneficio se contribuye al beneficio general, queda expresado en la contradicción entre egoísmo/solidaridad que plantea la entrevistada. Más aún, este postulado de Adam Smith fue resignificado por la racionalidad de gobierno neoliberal a partir de la noción de reciprocidad. Para Hayek (1982), el orden del mercado ${ }^{14}$ no descansa en propósitos comunes sino en la reciprocidad, es decir, en la reconciliación de propósitos diferentes para el beneficio mutuo de los participantes. La reciprocidad resignifica, bajo el orden del mercado, el primitivo instinto de solidaridad (Hayek, 1981) que sirve bien al grupo pequeño pero que estamos obligados a olvidar en la mayoría de nuestros esfuerzos por ayudar a vivir a nuestros semejantes, resultado de nuestra obediencia a las reglas de propiedad ${ }^{15}$.

La tendencia hacia la universalización de la solidaridad (y de la reciprocidad), precisamente, se centra el gobierno de lo posible que se vincula con la construcción de una dimensión fundamental de los poderes híbridos: el ontopoder. Este último, no radica en el gobierno de lo que es o debe ser, sino de lo que puede ser. Alberga una forma específica de ejercicio de poder que se esconde tras la idea de po-

14 El orden espontáneo del mercado o catalaxia que deriva del antiguo verbo griego katallatein que da sentido no sólo a "traficar" y "cambiar" sino también de "admitir en la comunidad" y "convertir al enemigo en amigo" (Hayek, 1982:184).

15 Según el autor, esta nueva tradición moral fue un proceso de evolución selectiva que no debemos llamar darwiniano porque depende de la herencia de características adquiridas que Darwin excluyó, por ello, se trata de una variante de la evolución lamarckiana. Para que la gente aprenda cosas contrarias a sus instintos heredados se necesitan sanciones, especialmente, provenientes de la moral y la religión (Hayek, 1981:74-75). 
tencia. La aceptación de lo impuesto es percibida como parte de la propia "naturaleza". La ética de gobierno de sí opera sobre dichas potencialidades afectivas dentro del perímetro establecido por el orden del mercado. De este modo, se obtura la discusión en relación a que la "economía social y solidaria" coexiste en el sistema capitalista, lo cual plantea relaciones paradójicas.

\section{Referencias bibliográficas}

ANTUNES, R. Los sentidos del trabajo. Ensayo sobre la afirmación y la negación del trabajo. Segunda edición ampliada. Buenos Aires, Ediciones Herramienta, 2013.

DE BÜREN, P. “De la teoría objetiva a la teoría subjetiva del valor, de Smith a Menger. ¿De la teoría del valor trabajo a la teoría del valor capital?”, en: Revista Realidad Económica, N²63, octubre/noviembre, 2011. Pp. 17-42.

DE MELO LISBOA, A. “Solidaridad”, en: CATTANI, A. D. (Org.) La otra economía. Buenos Aires, Altamira, 2004. Pp. 389-401.

ELIZALDE HEVIA, A. "El pensamiento solidario como factor de desarrollo", en: Revista Ser Solidario, N5, 2011. Pp. 15-44.

ENGELS, F. y MARX, K. Ludwig Feuerbach y el fin de la filosofía clásica alemana. Moscú, Editorial Progreso, 1980.

FEUERBACH, L. La esencia del cristianismo. Buenos Aires, Claridad, 2006.

FOUCAULT, M. “El juego de Michel Foucault”, en: Saber y verdad. Madrid, Ediciones de la Piqueta, 1984. Pp. 127-162. [En línea: 11 de mayo de 2015] Disponible en: http:// www.con-versiones.com.ar/nota0564.htm

FOUCAULT, M. El nacimiento de la biopolítica. Curso en el Collège de France (19781979). Buenos Aires, FCE, 2008.

FOUCAULT, M. Seguridad, territorio, población. Curso del Collège de France (19771978). Buenos Aires, FCE, 2007.

FOURIER, C. El nuevo mundo amoroso. Madrid, Editorial Fundamentos, 1975.

FOURIER, C. El nuevo mundo industrial y societario. 1989. [En línea: 17 de agosto de 2013] Disponible en: http://www.eumed.net/cursecon/textos/fourier_nuevo-mundo.htm.

GAIGER, L. I. "La solidaridad como una alternativa económica para los pobres”, en: Revista de Economía Pública, Social y Cooperativa. N³1, 1999. Pp. 187-205.

GODELIER, M. El enigma del don. España, Paidós, 1996. 
HAYEK, F. "Los fundamentos éticos de una sociedad libre”, en: Revista Estudios Públicos. $\mathrm{N}^{\circ}$ 3, 1981. Pp. 70-82.

HAYEK, F. "Los principios de un orden social liberal”, en Revista Estudios Públicos. $N^{\circ}$ 6, 1982. Pp. 179-202.

HINTZE, S. Trueque y Economía Solidaria. Buenos Aires, Editorial Prometeo, 2003.

HUME, D. Tratado de la naturaleza humana. Argentina, Ediciones Orbis, 1984.

KOSIC, K. Dialéctica de lo concreto. México, Grijalbo, 1967.

MARX, K. El Capital. Capítulo VI (inédito). México, Siglo XXI, 2001.

MARX, K. y ENGELS, F. El verdadero socialismo. 1959. [En línea: 5 de octubre de 2014] Disponible en: http://www.marxists.org/espanol/m-e/1846/ideoalemana/index. htm.

MELARAGNO, M. "Diseño, aprendizajes e inclusión”, en: GALLARDO, V. C. y SCAGLIA, J.C. (Coord.) Diseñar la inclusión, incluir al diseño: aportes en torno al territorio de convergencia entre diseños y políticas sociales. Martínez, Ediciones Azzurras, 2011. Pp. 91-111.

MISES, L. La acción humana. Tratado de economía. Madrid, Unión Editorial, 1986.

PRESTA, S. "Consideraciones acerca de la economía social y solidaria. El trágico sentimiento de esperanza”, en: Revista Cátedra Paralela $\mathrm{N}^{\circ} 10$, Rosario, UNR Editora, 2013. Pp. 234-346.

RAZETO MigLiARO, L. Actitudes metodológicas de Nueva Civilización. Santiago de Chile, Editorial Universitas Nueva Civilización, 2013.

RAZETO, L. “El Factor “C””. Entrevista. 1997 [En línea: 20 de junio de 2014] Disponible en: http://www.luisrazeto.org.

SMITH, A. Investigación sobre la naturaleza y causas de la riqueza de las naciones. México, FCE, 1958.

SMITH, A. La teoría de los sentimientos morales. Madrid, Alianza, 2009.

ZIŽEK, S. En defensa de la intolerancia. Madrid, Ediciones Sequitur, 2008.

ZIŽEK, S. Amor sin piedad. Hacia una política de la verdad. Madrid, Editorial Síntesis, 2004.

Recepción: 15/05/2015

Aceptación: 23/06/2015 